\title{
Variability of atmospheric circulation patterns associated with large volume changes of the Baltic Sea
}

\author{
A. Lehmann ${ }^{1}$ and P. Post ${ }^{2}$ \\ ${ }^{1}$ GEOMAR Helmholtz Centre for Ocean Research, Kiel, Germany \\ ${ }^{2}$ Institute of Physics, University of Tartu, Tartu, Estonia \\ Correspondence to: A. Lehmann (alehmann@geomar.de)
}

Received: 25 January 2015 - Revised: 10 August 2015 - Accepted: 15 October 2015 - Published: 29 October 2015

\begin{abstract}
Salinity and stratification in the deep basins of the Baltic Sea are linked to the occurrence of Major Baltic Inflows (MBIs) of higher saline water of North Sea origin, which occur sporadically and transport higher saline and oxygenated water to deeper layers. Since the mid-1970s, the frequency and intensity of MBIs have decreased. They were completely absent between February 1983 and January 1993. However, in spite of the decreasing frequency of MBIs, there was no obvious decrease of larger Baltic Sea volume changes (LVCs). A LVC is defined by a total volume change of at least $100 \mathrm{~km}^{3}$. LVCs can be identified from the sea level changes at Landsort which is known to represent the mean sea level of the Baltic Sea very well. Strong inflows leading to LVCs are associated to a special sequence of atmospheric circulation patterns. Our analysis based on JenkinsonCollison circulation (JCC) types confirms that most effective inflows occur if about a month before the main inflow period, eastern air flow with anticyclonic vorticity over the western Baltic prevails. These conditions reduce the mean sea level of the Baltic Sea and lead to an increased saline stratification in the Belt Sea area. An immediate period of strong to very strong westerly winds trigger the inflow and force LVCs/MBIs. The lack of MBIs coincide with a negative trend of eastern types and a parallel increase of western type JCCs.
\end{abstract}

\section{Introduction}

The salt budget of the Baltic Sea (Fig. 1) is determined by a balance between saline inflow from the Kattegat and brackish water outflow from the Baltic Sea through the Danish Straits. River runoff and precipitation cause dilution while evaporation acts in the opposite direction. Ice formation and melting act as evaporation and precipitation, respectively, but have no influence on an annual timescale. Generally, during dry periods the mean salinity of the Baltic Sea increases while during wet periods a decrease will happen. These long-term changes are overlaid by the atmospheric-driven water exchange between the North Sea and the Baltic Sea. Moderate saline waters flow in permanently, but highly saline inflows that are able to replace the stagnant bottom waters, happen relatively rarely.

The salinity and stratification in the deep basins are linked to the occurrence of major Baltic inflows (MBIs) which occur sporadically and transport highly saline and oxygenated water of North Sea origin to deeper layers of the Baltic Sea. These major inflows are often followed by stagnation periods with no strong saline inflows, during which the permanent halocline weakens, even disappears in some basins, and extended areas of oxygen deficiency develop in those regions where the salinity stratification remains (Leppäranta and Myrberg, 2009, Väli et al., 2013). Since the early eighties the frequency of highly saline inflow events has dropped drastically from 5 to 7 events per decade to only one inflow per decade. Major inflow events occurred in January 1993 and 2003. After more than 10 years without major Baltic inflows, in December 2014 a strong MBI brought large amounts of saline and well oxygenated water into the Baltic Sea (Mohrholz et al., 2015).

In spite of the decreasing frequency of MBIs and increasing periods of stagnation, large volume changes (LVCs) of the Baltic Sea still took place which were reflected in the mean sea level of the Baltic Sea (Franck and Matthäus, 1992; Lehmann et al., 2002). A LVC is typical to occur in the Baltic 


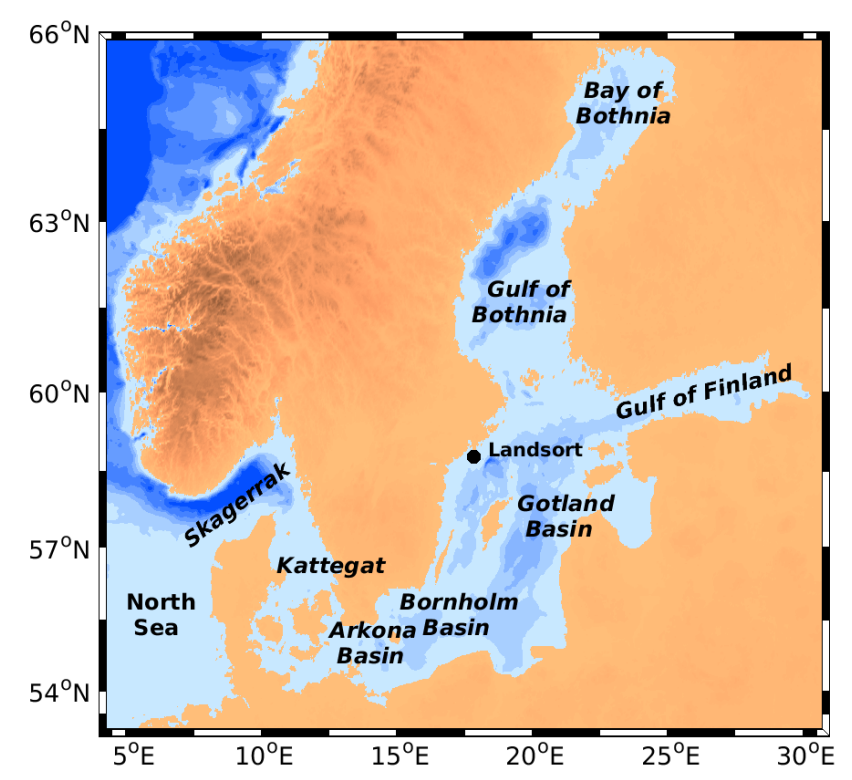

Figure 1. Map of the Baltic Sea and marked position of the Landsort tide gauge.

Sea, being connected to favorable atmospheric forcing, but these do not always lead to MBIs even if the incoming water volumes might be large. The difference between MBI and LVC is that during a LVC only relative low-saline water can be re-imported to the Baltic Sea. A MBI is always related to an effective salt transport which is able to substitute the bottom water in the deep basins of the Baltic Sea. Thus, MBIs can be considered as subset of LVCs transporting additionally to the large water volume a huge amount of salt into the Baltic Sea. Large volume changes have also been observed in previous studies (Jacobsen, 1981; Lass and Schwabe, 1990). The associated volume change is typically about $100 \mathrm{~km}^{3}$ and the duration is about 40 days (Lehmann et al., 2002).

Atmospheric conditions leading to MBIs have comprehensively been studied (e.g. Schinke and Matthäus, 1998; Lass and Matthäus, 1996; Matthäus and Schinke, 1994). Strong inflows are associated with certain sequences of atmospheric flow patterns over the larger North Atlantic/North European region. The atmospheric forcing of major Baltic inflows has two phases: at first, high atmospheric pressure over the Baltic region with easterly winds followed by several weeks of strong westerly winds over the North Atlantic and Europe. The intensity of single events depends on how well both phases are developed and how closely they are related in time. Previous studies concentrated mostly on MBI periods, describing the average situation during and before the events, but also trying to find some earlier predictors of the events.

Recently, Schimanke et al. (2014) presented an algorithm based on mean sea level pressure (MSLP) fluctuations to identify major Baltic inflow events. The algorithm which used daily SLP-fields as only parameter identified the majority of major inflow events between 1961 and 2010. Fur- thermore, they found more favorable atmospheric conditions for inflow events than have been identified by observations. They argued that in spite of favorable atmospheric conditions other factors such as runoff could prevent MBIs. It is reasonable to assume that the atmospheric forcing of MBIs and LVCs should be similar. As LVCs and MBIs are very variable in length and intensity we tried to find common characteristics and to somehow generalize the pressure fields and their sequences.

One possible method to aggregate the main variability of atmospheric pressure patterns into a reasonable small set of patterns is using classifications of atmospheric circulation types (Huth et al., 2008). Circulation type classification (CTC) is widely used in order to describe the variability of pressure patterns in a certain domain. During this process exact information about the individual configuration of the pressure field is lost, replaced by a single number per pressure field and by a sequence of circulation type numbers for periods of time. Regardless of losing detailed information, suitably chosen classification methods reduce also noise which might be seen as advantage. The gain is the simplicity of the result, which makes it attractive for a wide range of applications dealing with the linkage between largescale circulation and weather-related surface conditions. If any relationship between the occurrence of a distinct circulation type and an associated surface condition is detected, this technique easily offers insights into physical reasons for this relationship. In recent years, there has been a real avalanche of papers with applications from many fields beginning from searching trends in temporal variability of atmospheric circulation to climate models output downscaling.

The idea of this paper is to separate the atmospheric conditions necessary to force large volume changes of the Baltic Sea. We studied the atmospheric circulation patterns forcing LVCs by Lamb automated weather types (Jenkinson and Collison, 1977) or synoptic weather types that are easily interpretable. With the knowledge of sequences of main patterns which cause large inflows to the Baltic Sea, it is possible to analyze the variability of these patterns in time to reveal possible changes in the atmospheric circulation which potentially could explain the lack of large inflows in recent decades.

\section{Materials and methods}

\subsection{Sea level data at Landsort}

Hourly sea level data at the tide gauge station Landsort in Sweden (Fig. 1) have been downloaded from the SMHI Öppna data bank system (http://opendata-download-ocobs. smhi.se/explore/) for the time period 1887-2013. Sea level data have been detrended from effects of land uplift and climate change. Furthermore, to reduce local effects of sea level changes daily averages have been calculated. Landsort sea level data are known to describe mean sea level changes of 


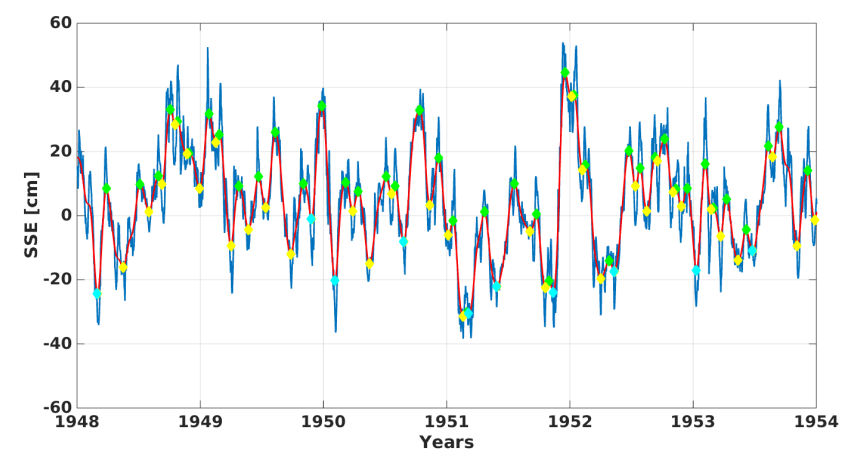

Figure 2. Sea surface elevation daily averages (blue) and filtered curve (red) at Landsort tide gauge for the period 1948-1954, minima (yellow) and maxima (green) as well as detected LVCs (cyan) based on the threshold of $29 \mathrm{~cm}$.

the entire Baltic Sea very well (Franck and Matthäus, 1992). The up- and down movements can be related to corresponding volume transports through the entrance area of the Baltic Sea (Lehmann et al., 2002). The mean sea level of the Baltic Sea is a function of in- and outflow through the Danish Straits and the net fresh water flux. Due to the limited transport capacity of the Danish Straits, sea level changes in the Kattegat result in a delayed response of the mean sea level. The entrance area of the Baltic Sea acts as a low-pass filter for signals entering from the Kattegat, short-term variations are effectively filtered out (e.g. Andersson, 2002).

The main interest of our study are sea level changes occurring on weekly to monthly timescales, thus being evident in the mean sea level variation. So we used the method proposed by Pasanen et al. (2013) to smooth the sea level time series and filter out high frequency fluctuations. Pasanen et al. (2013) proposed a method for extracting time series features in different scales. It produces a multi-resolution analysis of the time series as the sum of scale-dependent components. These components were obtained from differences of smooth. The smoothing levels were determined using derivatives of smooths of the original time series. Details of the multi-resolution method for extracting time series features may be found in Pasanen et al. (2013).

From the smoothed curve local minima and maxima of the sea level have been determined. Furthermore, from the difference between minima and maxima we detected larger inflows resulting in large volume changes. A LVC is defined by the sea level difference of at least $29 \mathrm{~cm}$ corresponding to about $100 \mathrm{~km}^{3}$ of volume change. Figure 2 shows the original and smoothed time-series of sea surface elevation (SSE) for the period 1948-1954 which includes the strongest MBI so far in December 1951. This inflow resulted in a total volume change of about $240 \mathrm{~km}^{3}$ (Fig. 3). For the threshold of $29 \mathrm{~cm}$ we determined all LVCs from the smoothed times series of sea level/volume changes at Landsort occurring over the period from 1948-2010 (Fig. 3). All in all 74 LVCs have been detected. Nearly all MBIs coincide with LVCs, differences are due to the applied smoothing of the sea level time-series. This gives confidence that the applied method is suitable to detect LVCs.

On average LVCs were associated with about $40 \mathrm{~cm}$ of sea level difference, $141 \mathrm{~km}^{3}$ of volume change (inflow) over a period of about 53 days. It should be noted that these events are very different from the point of view of inflow duration or time between maximum and minimum SSE values, ranging from 31 to 116 days. The main season of LVCs is from October to December (OND, $42 \%$ ), followed by January-March (JFM, $22 \%$ ), April-June (AMJ, $20 \%$ ) and July to September (JAS, $15 \%)$.

\subsection{Atmospheric circulation classification}

We classified air pressure patterns in order to describe the variability of atmospheric circulation in the Baltic Sea region. The classification of circulation weather types developed by Jenkinson and Collison (1977) as an automatic version of Lamb's classification (Lamb, 1972) was selected because of the interpretation simplicity. The latter offers easy comparison of circulation types frequencies over different domains. It is widely used elsewhere in Europe (e.g. Trigo and DaCamara, 2000; Post et al., 2002; Linderson, 2001; Jones et al., 2013).

MSLP values from 16 points in and around the study area (Fig. 4) are used to calculate 6 different flow indices, which quantify the geostrophic airflow and vorticity (see Post et al., 2002 for details). Jenkinson Collison' circulation types (JCT) and classes (JCC) are defined by comparing the numeric values of the indices. There are altogether 26 circulation types that could be merged to 10 classes. If a straight airflow dominates over the vorticity then, depending on the direction of the flow, 8 directional types are specified (W, $\mathrm{NW}, \mathrm{N}, \mathrm{NE}, \mathrm{E}, \mathrm{SE}, \mathrm{S}, \mathrm{SW}$ ). If the vorticity $Z$ is at least two times larger than the geostrophic flow $F$, then the cyclonic (C) or anticyclonic (AC) types are assigned. There are also 16 so-called hybrid types: 8 cyclonic and 8 anticyclonic ones where the geostrophic flow and positive or negative vorticity play a nearly equal role in atmospheric regional circulation. In case of circulation classes the hybrid types are added to the directional ones, resulting in 10 main circulation classes.

Mean sea level pressure fields for 10 JCCs centered at the Danish Straits $\left(55^{\circ} \mathrm{N}, 10^{\circ} \mathrm{E}\right)$ are represented in Fig. 4. The center over the Danish Straits was selected in relation to previous studies (Matthäus and Schinke, 1994; Lass and Matthäus, 1996).

JCTs and JCCs were calculated for all days during the period of 1948-2013 using gridded MSLP data of NCEP/NCAR reanalysis (Kalnay et al., 1996) at 12:00 UTC. The software package cost733class (Philipp et al., 2014) was used as it offers a flexible way to calculate several circulation classifications with variable number of types over arbitrarily selected areas. 

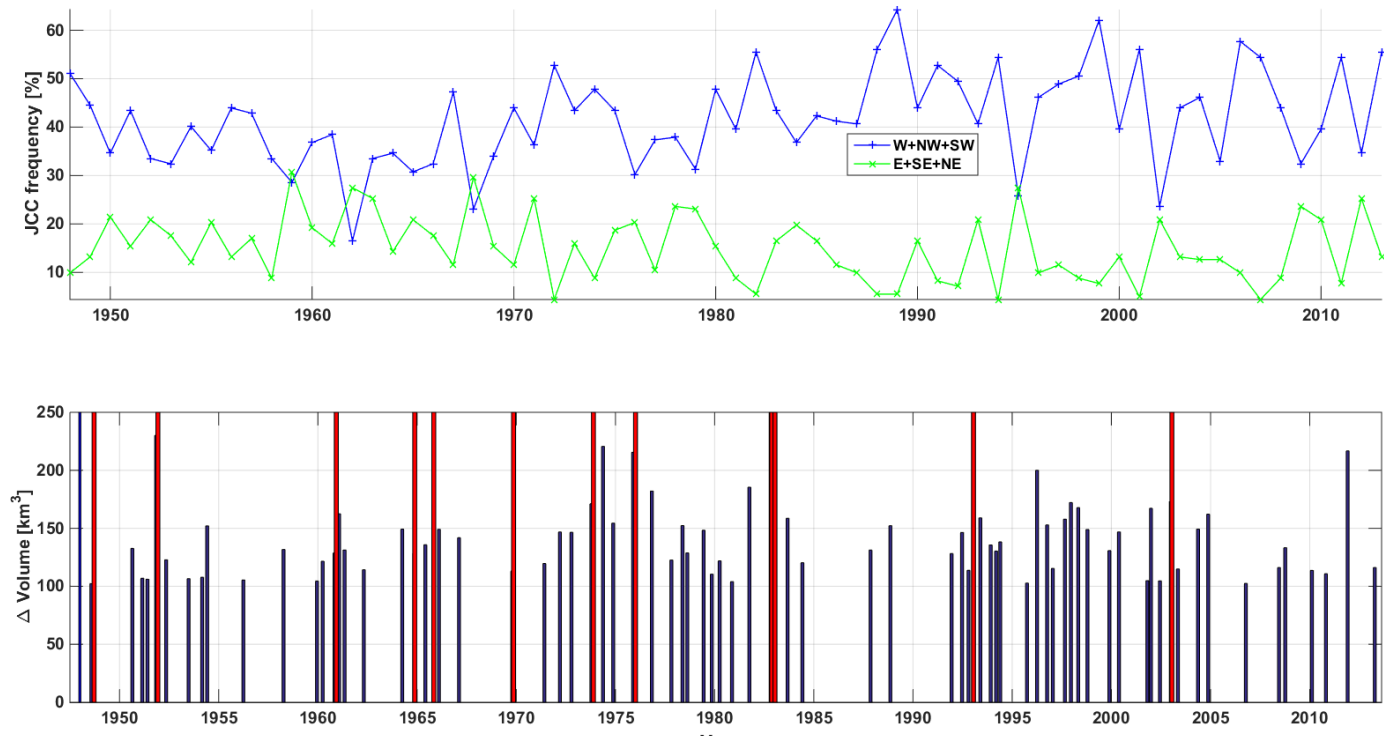

Figure 3. Upper panel: relative frequencies (\%) of selected JCCs: $\mathrm{W}+\mathrm{NW}+\mathrm{SW}$ (blue line) and $\mathrm{E}+\mathrm{SE}+\mathrm{NE}$ (green line) for the half-year period October to March (ONDJFM), lower panel: detected LVCs (blue bars) based on smoothed sea surface elevation at Landsort for the period 1948-2013. Red bars mark MBIs (Matthäus et al., 2008).
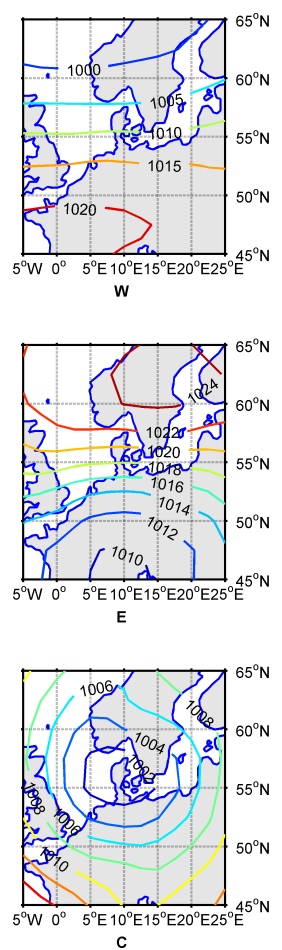
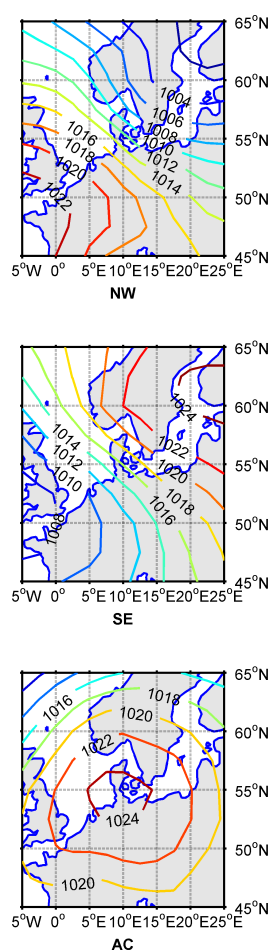
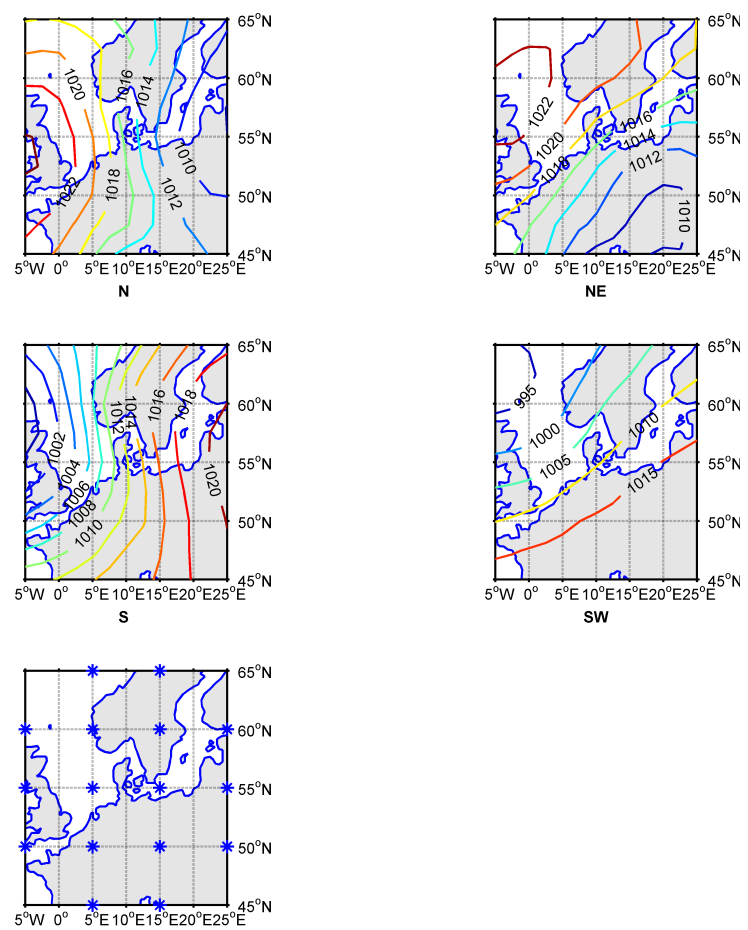

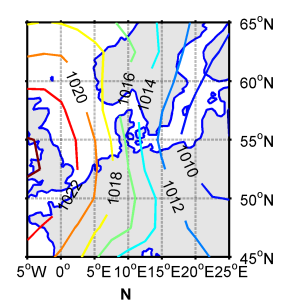

Figure 4. MSLP fields (in hPa) for 10 Jenkinson-Collison circulation classes (JCC) centered over the middle of the Danish Straits at $10^{\circ} \mathrm{E}$, $55^{\circ} \mathrm{N}$. In the right lower panel the geographical positions of 16 data points which are used for the JCC-calculations is shown. 


\section{Results}

\subsection{Atmospheric circulation patterns prevailing during LVC periods}

Mean annual and seasonal frequencies of circulation classes were calculated to compare the special circulation during the $74 \mathrm{LVC}$ periods with the mean atmospheric circulation in this domain. For each LVC, periods of 121-days were under closer inspection. Based on Landsort SSE data it is reasonable to center the periods either on the day of the minimum or the maximum sea level, or the day in the middle between them. We call this reference time 0-day. At first we tested the sensitivity of JCC sequences with respect to the 0 -day selection. Sequences of circulation classes for 74 large volume changes of the Baltic Sea in the period 19482013 with 0-days at (a) minimum and (b) maximum Landsort SSE are presented in Fig. 5. The images appear to be somewhat noisy because of the high variability of the circulation classes during the LVC periods. There is obviously not just one sequence of patterns that results in large volume changes. The first structure, that could be noticed is a greenish yellow stripe before the 0-day (Fig. 5a), that demonstrates dominating easterly and southeasterly atmospheric flow (class) before the minimum of SSE at Landsort. A similar noisy pattern can also be found in Fig. 5b associated with dominating westerly and north-westerly atmospheric flow (class) before the maximum of SSE at Landsort. The patterns in Fig. 5a are shifted to the left with respect to the chosen reference but the structure of the patterns are very similar. The high variability in the length of LVC periods makes the synthesizing of the atmospheric circulation difficult. Thus, we have calculated frequency histograms for 30-day sub-periods, for which the circulation patterns are more homogeneous. These are presented in Fig. 6 for three 30-day sub-periods taking the 0 -day at SSE maximum. The first sub-period corresponds to the pre-inflow period (60 to 31 days before the 0-day), the second sub-period corresponds to the inflow period (30-days until the 0-day), and the third sub-period, after the inflow, is chosen as a control period (1-30 days after the 0 -day). The relative frequencies of JCCs in dependency of varying LVC thresholds are also displayed in Fig. 6. The threshold has been varied in the range of 24 to $44 \mathrm{~cm}$. The significance of the difference in frequency distributions between the 19482013 average JCCs (bright green columns in Fig. 6) and the corresponding sub-period is checked by the KolmogorovSmirnov test. The JCCs histogram for the third sub-period never differed from the long-term mean. For the whole 121day period and for the second sub-period the histogram differed significantly from the long period mean in case of all used thresholds. The first sub-period was significantly different from the mean for $24-38 \mathrm{~cm}$ LVC thresholds, but failed the test in case of higher SSE values. In case of larger LVCs, the duration of the inflow is generally longer (more than 30 days) and in case of higher SSEs the separation of the pre-
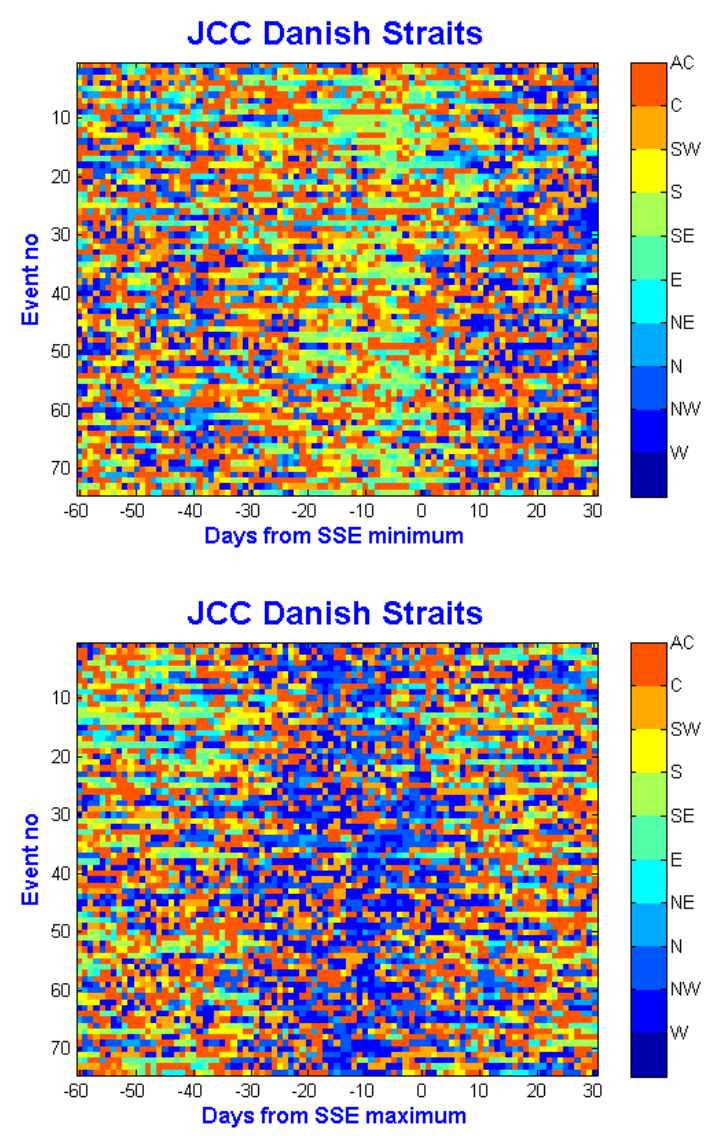

Figure 5. Sequences of Jenkinson-Collison circulation classes for 91-days periods during $74 \mathrm{LVC}$ events. Upper panel: the 0-day is centered at the minimum sea surface elevation at Landsort, lower panel: the 0-day is centered at the maximum sea surface elevation at Landsort.

inflow period and the main inflow period is not always possible (therefore, the percentage of W, NW and SW grows at higher thresholds, Fig. 6a).

For the chosen $100 \mathrm{~km}^{3}(29 \mathrm{~cm})$ threshold, during the precursory period (30-days before the minimum in Landsort SSE) the largest increase compared to long-term mean frequency show SE and E types of JCCs. During the inflow period (30-days before the maximum in Landsort SSE) the dominant JCCs are W and NW. From Fig. 6, it could be deduced that the frequency of these specific circulation classes grows if the threshold is increased.

To check if it is possible to associate the temporal changes in the number of LVCs and MBIs with the changes in atmospheric circulation, annual and seasonal occurrences of separate and combined JCCs were calculated for every year. As season, we defined the main period when most of the MBIs occurred (October to March, ONDJFM). The Mann-Kendal nonparametric test (Kendall, 1975) was applied to check the significance $(p=0.05)$ of the trends in JCCs frequencies. For two classes (W, SW) positive trends and also for two 

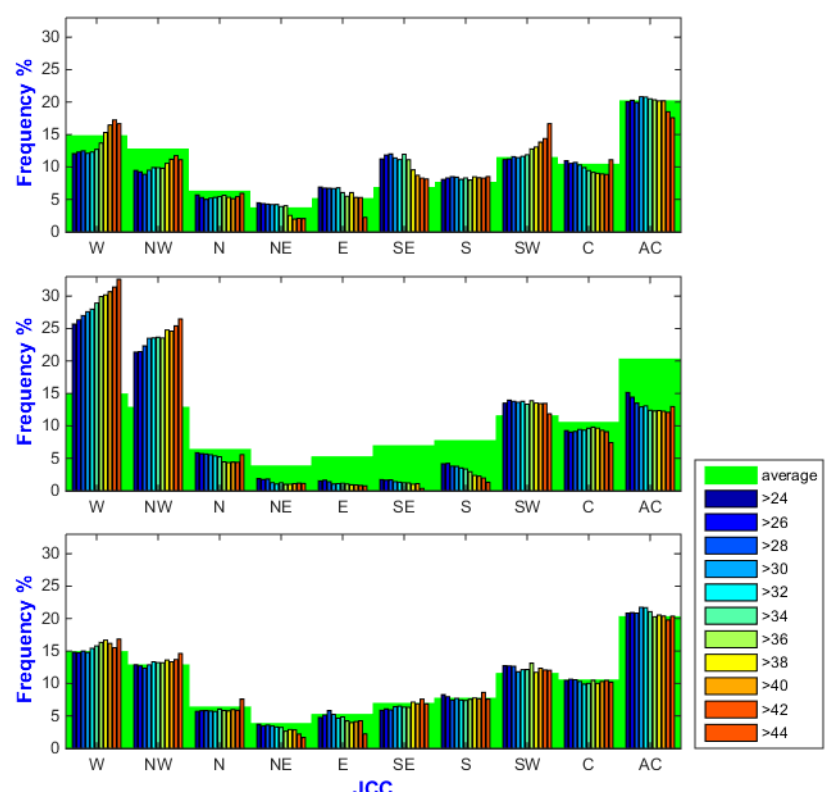

Figure 6. Histograms of occurrences of JCCs for LVC periods: (upper panel) 60-31 days before (upper panel), 30-0 days before (middle panel), and 1-30 days after (lower panel) the SSE maximum at Landsort. The threshold of LVCs varies between 24 to $44 \mathrm{~cm}$.

classes negative trends (NE, E) during the 66 seasons were found. Trends determined for time series of seasonal occurrences of $\mathrm{NE}+\mathrm{E}+\mathrm{SE}$ and $\mathrm{SW}+\mathrm{W}+\mathrm{NW}$ were also significant (see Fig. 3). The occurrence of these easterly types has decreased since 1970s about 20 days, while for the westerly types the frequency has grown about twice. Slopes of trends were calculated by the method of Sen (1968).

\section{Conclusions and discussion}

A new term "Large Volume Changes (LVCs)" has been introduced to indicate changes in the Baltic Sea volume independent of the salinity content of the inflowing water mass. The idea is based on the assumption that the atmospheric forcing that causes the inflows to the Baltic Sea does not depend on salinity. Large volume changes have been calculated for the period 1948-2013 filtering Landsort sea surface elevation anomalies daily time series. The cases with local minimum and maximum difference of at least $29 \mathrm{~cm}$ which correspond to $100 \mathrm{~km}^{3}$ of Baltic Sea volume change have been chosen for a closer study to reveal atmospheric circulation patterns that force large changes in volume. The total number of such cases is 74 .

For the first time, atmospheric circulation classification has been used to characterize the atmospheric forcing before, during and after the LVC events. From earlier studies, it could be deduced that these events are driven by synoptic scale atmospheric forcing, which could easily be represented and interpreted by Lamb automated weather types (Jenkin- son and Collison, 1977). During different phases of the inflow, the abundance of certain Jenkinson Collison' classes grow or decrease compared to the average frequency of classes. The frequency distributions of Jenkinson Collison' classes 60-30 days before the maximum SSE is significantly different from the average and the same is valid for the period of 30-0 days before the maximum, but not for the 30 days period after the maximum. The first period is characterized by a higher number of $E$ and $S E$ classes, which confirms the idea of Matthäus and Schinke (1994) about the pre-inflow period for which easterly winds prevail which increase the Baltic Sea water outflow, lower the mean sea level and hinder the inflow of North Sea water through the Danish Straits. The associated anticyclonic circulation is related to dry periods with less precipitation and increased saline stratification in the Belt Sea area. An immediate period (next 30 days) of strong to very strong westerly winds trigger the inflow and force effective LVCs/MBIs.

If the threshold for a LVC is raised, the amount of certain aforementioned types increases during both 30 days periods. It is difficult to attribute the lack of MBIs to the increase or decrease of certain JCCs, but the trends in time series of $\mathrm{NE}+\mathrm{E}+\mathrm{SE}$ and $\mathrm{SW}+\mathrm{W}+\mathrm{NW}$ show that the reason can be the negative trend in eastern types after 1980s, as in the western types for which a significant increase occurred. Thus, one possible reason might be the increased atmospheric zonal circulation linked with intensified precipitation in the Baltic region and increased river runoff to the Baltic Sea (Schinke and Matthäus, 1998; Lehmann et al., 2002, 2011). An alternative explanation has been recently proposed by Soomere et al. (2015). They found a significant abrupt change in the meridional component of the airflow direction over the southern Baltic Sea around 1987. This change was established by a substantial increase in northwestern wind events at the expense of other wind directions (e.g. western winds that are critical for MBIs to occur).

We showed that easily interpretable circulation types in synoptic scale offer a complex tool to study the atmospheric forcing of large volume changes to the Baltic Sea. But such a simple circulation classification as JCC with only 10 classes does not reveal very special circulation cases, that could be connected to MBIs. An inverted approach could be used, at first classifying only pressure fields occurring during such events, and then in a second step determining their individual frequency. The main idea is that events like these depend on the sequence or accumulation of forcing which is not easy to follow by an Euler type approach. Therefore the next steps will be the tracking of cyclone pathways and classifying of pressure field sequences which will help to overcome this kind of problems. 
Acknowledgements. Circulation weather types have been calculated using software cost733class that has been worked out during COST action 733 at Augsburg University (http://cost733.geo. uni-augsburg.de/cost733class-1.2).

The study was supported by the Estonian Ministry of Education and Research (IUT20-11 and ETF9134) and by the EU Regional Development Foundation, Environmental Conservation and Environmental Technology R \& D Program Project no. 3.2.0801.12-0044.

The article processing charges for this open-access publication were covered by a Research

Centre of the Helmholtz Association.

Edited by: R. Huth

Reviewed by: three anonymous referees

\section{References}

Andersson, H. C.: Influence of long-term and large-scale atmospheric circulation on the Baltic Sea level, Tellus, 54A, 76-88, 2002.

Franck, H. and Matthäus, W.: Sea level conditions associated with major Baltic inflows, Beitr. Meereskunde, 63, 65-90, 1992.

Huth, R., Beck, C., Philipp, A., Demuzere, M., Ustrnul, Z., Cahynova, M., Kyseli, J., and Tveito, O. E.: Classification of atmospheric circulation patterns, Ann. N. Y. Acad. Sci., 1146, 105-152, doi:10.1196/annals.1446.019, 2008.

Jacobsen, T. S.: The physical oceanography of the open Danish waters, in: The Belt Project evaluation of the physical, chemical and biological measurements, edited by: Aetebjerg Nielsen, G., National Agency of Environmental Protection, Denmark, 122 pp., 1981.

Jenkinson, A. F. and Collison, F. P.: An initial climatology of gales over the North Sea, Synoptic Climatology Branch Memorandum, No. 62, Meteorological Office, Bracknell, 18 pp., 1977.

Jones, P. D., Harphan, C., and Briffa, K.: Lamb weather types derived from reanalysis products, Int. J. Climatology, 33, 11291139, doi:10.1002/joc.3498, 2013.

Kalnay, E., Kanamitsu, M., Kistler, R., Collins, W., Deaven, D., Gandin, L., Iredell, M., Saha, S., White, G., Woollen, J., Zhu, Y., Leetmaa, A., Reynolds, R., Chelliah, M., Ebisuzaki, W., Higgins, W., Janowiak, J., Mo, K. C., Ropelewski, C., Wang, J., Jenne, R., and Joseph, D.: The NCEP/NCAR 40-Year Reanalysis Project, B. Am. Meteorol. Soc., 77, 437-472, 1996.

Kendall, M. G.: Rank Correlation Methods, London, UK, Charles Griffin, 1975.

Lamb, H. H.: British Isles weather types and a register of daily sequence of circulation patterns, 1861-1971, Geophys. Mem., 110, Meteorol. Office, London, 85 pp., 1972.

Lass, H. U. and Matthäus, W.: On temporal wind variations forcing salt water inflows into the Baltic Sea, Tellus, 48A, 663-671, 1996.

Lass, H. U. and Schwabe, R.: An analysis of the salt water inflow into the Baltic in 1975 to 1976 , Dt. Hydrogr. Z., 43, 97-125, 1990.
Lehmann, A., Krauss, W., and Hinrichsen, H.-H.: Effects of remote and local atmospheric forcing on the circulation and upwelling in the Baltic Sea, Tellus, 54A, 299-316, 2002.

Lehmann, A., Getzlaff, K., and Harlass, J.: Detailed assessment of climate variability in the Baltic Sea area for the period 1958 to 2009, Clim. Dynam., 46, 185-196, 2011.

Leppäranta, M. and Myrberg, K: The physical oceanography of the Baltic Sea, Springer-Verlag, Berlin-Heidelberg-New York, 378 pp., 2009.

Linderson, M. L.: Objective classification of atmospheric circulation over Southern Scandinavia, Int. J. Climatol., 21, 155-169, 2001.

Matthäus, W., Nehring, D., Feistel, R., Nausch, G., Mohrholz, V., and Lass, H.-U.: The Inflow of Highly Saline Water into the Baltic Sea, In State and Evolution of the Baltic Sea, 19522005: A Detailed 50-Year Survey of Meteorology and Climate, Physics, Chemistry, Biology, and Marine Environment, 265-309, 2008.

Matthäus, W. and Schinke, H.: Mean Atmospheric Circulation Patterns Associated with Major Baltic Inflows, Dt. Hydrogr. Z., 46, 321-339, 1994.

Mohrholz, V., Naumann, M., Nausch, G., Krüger, S., and Gräwe, U.: Fresh oxygen for the Baltic Sea - An exceptional saline inflow after a decade of stagnation, J. Marine Syst., 148, 152-166, 2015.

Pasanen, L., Launonen, I., and L. Holmström: A scale space multiresolution method for extracting of time series features, Stat, 2, 273-291, 2013.

Philipp, A., Beck, C., Huth, R., and Jacobeit, J.: Development and Comparison of Circulation Type Classifications Using the COST 733 Dataset and Software, Int. J. Climatol., doi:10.1002/joc.3920, in press, 2014

Post, P., Truija, V., and Tuulik, J.: Circulation Weather Types and Their Influence on Temperature and Precipitation in Estonia, Boreal Environ. Res., 7, 281-289, 2002.

Schimanke, S., Dieterich, C., and Meier, H. E. M.: An algorithm based on sea-level pressure fluctuations to identify major Baltic inflow events, Tellus A, 66, 23452, doi:10.3402/tellusa.v66.23452, 2014.

Schinke, H. and Matthäus, M.: On the Causes of Major Baltic Inflows - an Analysis of Long Time Series, Cont. Shelf Res., 1, 67-97, 1998.

Sen, P. K.: Estimates of Regression Coefficient Based on Kendall's Tau, J. Am. Stat. Assoc., 63, 1379-1389, 1968.

Soomere, T., Bishop, S. R., Viska, M., and Räämet, A.: An abrupt change in winds that may radically affect the coasts and deep sections of the Baltic Sea, Clim. Res., 62, 163-171, 2015.

Trigo, R. M. and DaCamara, C. C.: Circulation Weather Types and Their Influence on the Precipitation Regime in Portugal, Int. J. Climatol., 20, 1559-1581, 2000.

Väli, G., Meier, H. E. M., and Elken, J.: Simulated halocline variability in the Baltic Sea and its impact on hypoxia during 1961-2007, J. Geophys. Res., 118, 6982-7000, doi:10.1002/2013JC009192, 2013. 